\title{
The Intermesh of Records Management Principles and Enterprise Architecture A Framework for Information Governance in the Swedish Context
}

\author{
Anneli Sundqvist \\ OsloMet - Oslo Metropolitan University, Norway \\ annsu@oslomet.no \\ Tom Sahlén \\ Sahlén Arkivkonsult AB, Sundsvall, Sweden \\ info@arkivkonsulthb.se \\ Mats Andreasen \\ Blitt, Sweden \\ mats.andreasen@gmail.com
}

\begin{abstract}
Summary
To capture and control records generated in complex processes, involving many different actors in fluid constellations, organizations need tools that extends the range of traditional records management practices. Records management needs to be incorporated in more encompassing information governance regimes and integrated with the organizations' overall management systems. The authors argue that the intermesh of records management principles and Enterprise Architecture is a fruitful approach in the development of coherent information governance regimes. The paper presents a framework for information governance based on records management principles and Enterprise architecture and a methodological approach how to develop and implement information governance solutions by integrating records management with Enterprise Architecture using agile methods, Design thinking and User Experience Design (UX). The work is based on literature reviews and modelling workshops and is a result of an on-going development project aiming at methodological development to improve records management practice.
\end{abstract}

Key words: information governance, records management, enterprise architecture, agile methods

\section{Introduction}

The development of information technology in interplay with social and political changes has brought about a considerable shift in communication practices, production and work processes. One effect of these changes will be vast amounts of information. A fair amount of this information will constitute records and object to records and archives management. Records is here used as an inclusive concept that covers both transactional information, and information created and captured during business performance not as evidence of transactions, but because they represent some value or use for the organization. As lately has been more widely recognized, records are assets (ISO15489:2016; ISO/TR21965:2019). Assets that have to be managed and could add value to the organization (and to society), but also could be added value through appropriate management. In contemporary organizations records are not just the documentary result of business processes, they are integral to the processes, and, in some instances, the creation of records constitutes the actual performance of business activities. The management and control of records could thus not be undertaken as separate support functions external to the control of the business processes, but has to be integrated with the organizations' overall management systems. This means that holistic governance models are required, as well as methodological tools. Information governance (IG) is a concept that has been propagated within the field of information management and corporate governance the last 15 years, and it has also gained recognition within the records management community (Brooks, 2019; Hagmann, 2013). The alignment of RM with IG is advocated by several representatives of the RM sector, for instance 
Franks (2013), Lomas (2010) and ARMA International, whose Generally Accepted Recordkeeping Principles is promoted as a framework for good IG practice.

The purpose of this paper is to present a framework for information governance based on records management principles, and a methodological approach how to develop and implement information governance solutions by integrating records management with Enterprise Architecture using agile methods, Design thinking and User Experience Design (UX).

The paper is based on literature reviews and modelling workshops. It reports the work of an on-going development project aiming to produce guidelines for the implementation of information governance regimes in a Scandinavian context and to contribute to methodological development. The project is performed as a practical action research project (Denscombe, 2014), that is it addresses a specific problem within a particular community, records management professionals, to improve practice. The project group consists of a team including academic researchers, records professionals, IT-architects, all contributing with experience from their respective field of competence and with vast experience of Scandinavian records management practice.

\section{A framework for information governance}

A common definition of IG is Gartner's (2019) "the specification of decision rights and an accountability framework to ensure appropriate behavior in the valuation, creation, storage, use, archiving and deletion of information. It includes the processes, roles and policies, standards and metrics that ensure the effective and efficient use of information in enabling an organization to achieve its goals", which also is embraced by ARMA International. Usually IG involves compliance, information security, risk management, privacy, data management, big data, e-discovery, and archives and records management (e.g. Reed, 2017). The established definition of RM is a "field of management responsible for the efficient and systematic control of the creation, receipt, maintenance, use and disposition of records, including processes for capturing and maintaining evidence of and information about business activities and transactions in the form of records" (ISO 30300:2011, clause 3.4.3). RM could thus be seen as a subset of IG, with a more specific target and mandate (e.g. Hagmann, 2013; Lomas, 2010; Reed, 2017; Saffady, 2015). However, with a more inclusive conceptualization or records as suggested above, it could be argued that most information handled by IG would qualify as records. RM requirements could thus also apply to the management of other information resources (cf. ISO/TR 21965:219(E), p. v), in order "to ensure appropriate behavior in the valuation, creation, storage, use, archiving and deletion of information". The crucial notion here is, however, governance, here defined as "[t]he method by which and enterprise ensures that stakeholder needs, conditions and options are evaluated to determine balanced, agreed-on enterprise objectives are achieved. It involves setting direction through prioritization and decision making; and monitoring performance and compliance against agreed-on direction and objectives", which could be contrasted with management, which is about the planning, building, running and monitoring of "activities in alignment with the direction set by the governance body to achieve the enterprise objectives" (ISACA, 2019). Governance is about setting goals, deciding strategies, and defining roles and responsibilities, while management is about the control and execution of business activities. Governance is a matter for top management, but it can only be carried out with help of executive functions, e.g. RM functions, and management systems.

IG is today a well-known concept, but there is no established standard concerning general IG. Thus, the implementation of IG has to rely on the implementation of related frameworks and standards, e.g. ISO/IEC 38500, COBIT, ISO/IEC 27000, the aforementioned GARP, and not the least the ISO 30300 series - Management systems for records. A management system is "a set of interrelated or interacting elements of an organization to establish policies and objectives, and processes to achieve those objectives" (ISO 30300:2011, clause 3.4.1), and a management system for records (MSR) aims "to direct and control an organization with regard to records (ISO 30300:2011, clause 3.4.2). The implementation of a MSR would provide a basis for a comprehensive IG framework, requiring RM to be linked to the objectives of the organization. The following section will present a generic framework for RM adapted to Scandinavian and particularly Swedish conditions, developed as an outflow of continuing RM practice during more than 25 years (Bergbom et al., 1994; Bodin, Sahlén, Sjögren, 2000; Sundqvist, 2005; Sahlén, 2016). The framework takes its stance in the Swedish 
conceptualizations of records and archives and the established division of labour and responsibilities. By linking the framework to the requirements of ISO15489:2016 and the ISO30300-series, but also to some extent the ISO27000, a comprehensive IG regime could be established. Five generic ${ }^{1}$ RM functions are identified, that together with a management function perform the planning, execution and control of RM activities in an organization. Those functions should not be regarded as administrative units, and in practice there are no Chinese walls between them. They represent the fundamental measures that have to be taken to implement a good practice of RM - to guarantee the production, maintenance, preservation and reuse of records. In an analogue environment, those will usually be performed sequentially following a life-cycle perspective, but in the digital world they proceed in a continuum, partly parallel with each other. The management function has a central role, responsible for the control of the operational RM functions and the implementation of policies and strategies, organization, and processes of change decided by the top management (ISO 30301:2011, section 5). That is, the management function upholds the relationship with the overall governance system of the organization. See figure 5 below.

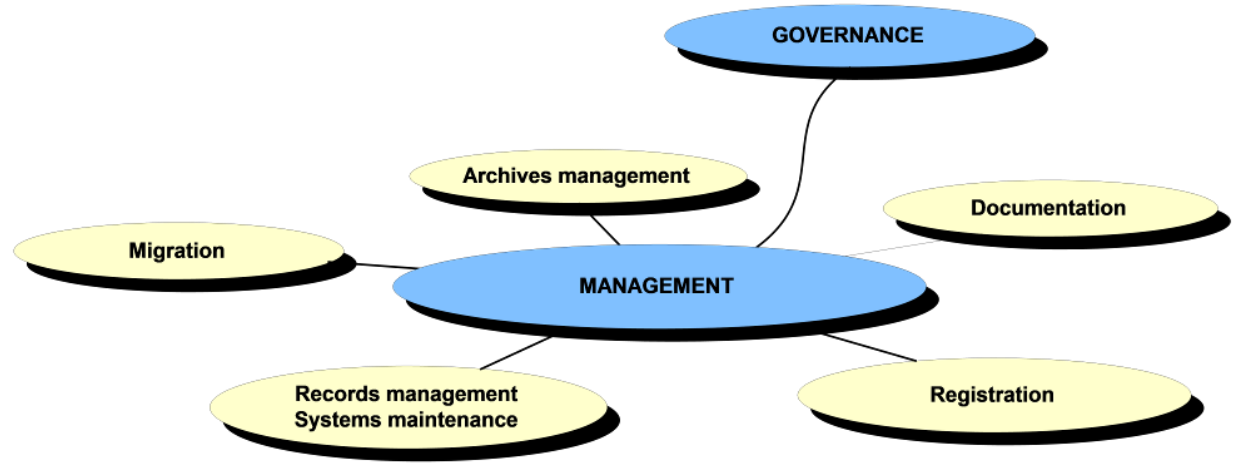

Figure 1. The RM Governance Model (Adapted from Sahlén, 2016: 180)

The role of the five generic RM functions could briefly be described as follows:

- documentation: identification of processes that should be documented; deciding what records that should be created or received; establishing requirements on records (cf. ISO 15489-1:2016, clause 5.2); establishing requirements on records systems (cf. ISO 15489-1:2016, clause 5.3).

- registration: capturing records, registration and journalizing; metadata records management and systems maintenance: administrative and technical maintenance; use and disposition of records and records system as long as they are in active use, including e.g. retention, access, storage and information security

- migration: the process of controlled transfer of records between systems and between the business environment and archival platforms

- archives management ${ }^{2}$ : long term management and preservation of semi-active or in-active records system requirements; archival description.

The functions are implemented and managed with help of four continuing activities that can be broken down to a work procedure, developed and maintained by the management function, figure 2 .

\footnotetext{
${ }^{1}$ Functions that exist in every records-creating organization, but not necessarily explicitly defined. Business processes will always be documented, records will be created and captured, managed, transferred and preserved, however not always in a planned and controlled manner or in compliance with legislation or standards.

${ }_{2}^{2}$ According to Scandinavian tradition, records management and archives management are closely connected and often performed by the same functions within the organizations.
} 


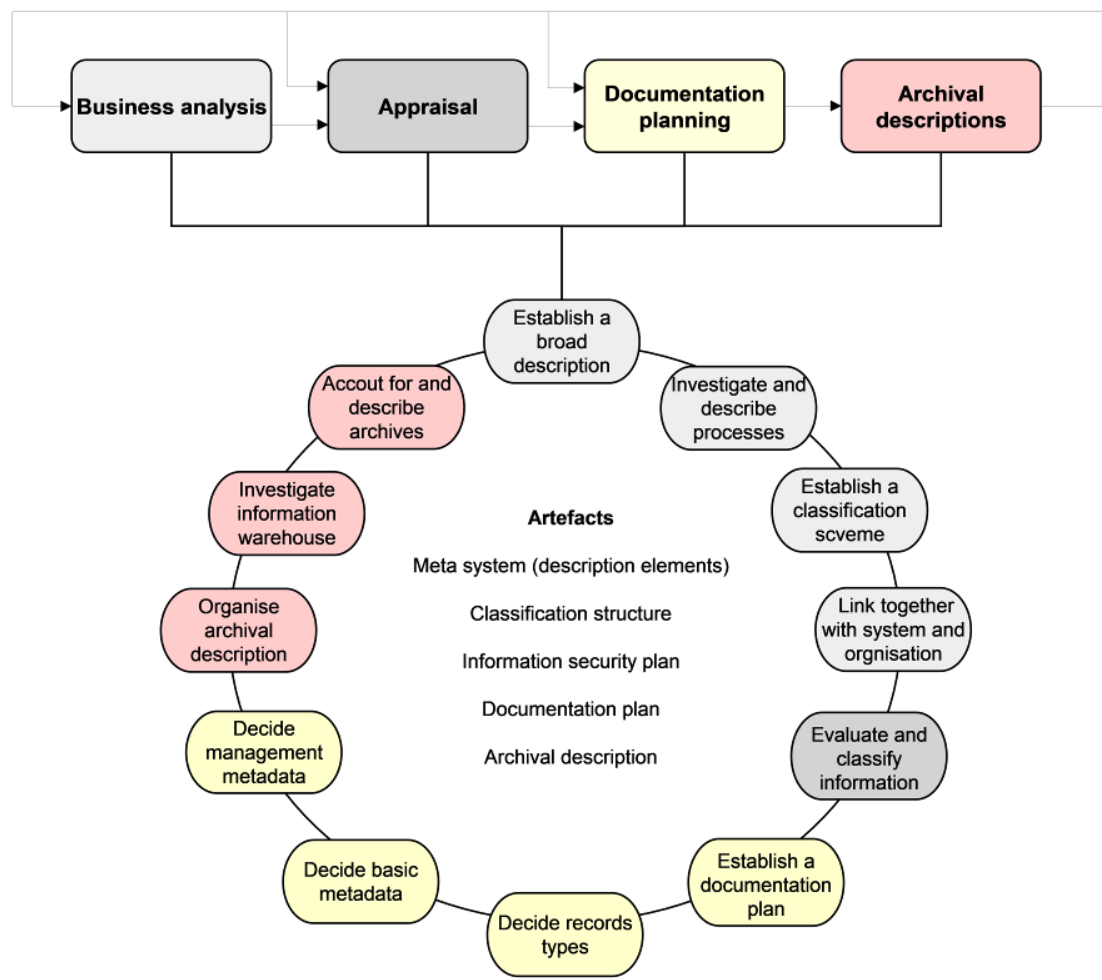

Figure 2. The RM Implementation Model (Sahlén 2016: 93)

The model can be applied both as a means for development and improvement, and for operational RM activities. It has a rather high level of abstraction, and has to be broken down, adapted to local needs, and supplemented with operational tools. ${ }^{3}$

The business analysis - analysis of business context, functions and processes - is the most vital activity that lays the foundation for the other steps in the process. The identification of records, the continuing need for them and the requirements to maintain authenticity, reliability, integrity and usability according to ISO15489:2016 should then be assessed, and the result systematized. The aim of EA is to survey and evaluate the current status, identify fields for improvement and transform the organization to a better state. This is also a component in a MSR, but from a RM perspective it is also necessary to capture the "now". This is a condition for establishing provenance and the evidential properties of records, but it is also a means for the continuing control and usability of records. Describing and cataloguing records is thus an integral component of the process. A result of those activities is a set of artefacts $^{4}$, instruments for description and control of records, of which the most important are:

- the metasystem - a systematic description of business functions including data about type, organizational affiliation, relation to other functional entities, records requirements, security classification, retention periods, relation to system and architecture entity (cf. International Council on Archives, 2007).

- a classification structure based on functions, processes and activities (ISO 15489-1:2016, clause 8.3)

- an information security plan based on a risk assessment (cf. ISO/IEC 27000)

\footnotetext{
${ }^{3}$ A prototype of a web application where the Implementation model forms basis for a RM toolbox, i.e. supplementing each step in the procedure with methodological guidelines, can be found at http://www.arkivkonsultab.se/manual-forinformationsforvaltning/

${ }^{4}$ Within EA and related disciplines, artefacts are products describing different aspects of the architecture (TOGAF 9.2, 2018, clause 3.20), and could "range from range from high-level principles to low-level technical diagrams (Kotusev, 2019: 103).
} 
- a documentation plan $^{5}$ - a compilation, based on the business classification scheme, documenting all types of (intra-organizational) records required in the business and rules for their management.

- an archival description (catalogue)

Those will then provide tools for the continuing RM cycles, and object to regular revision and improvement.

\section{Enterprise architecture}

A prerequisite for IG, and the above presented framework, is the incorporation of RM in more encompassing governance regimes and the organizations' overall management systems, which requires a purposive strategy and course of action. A viable strategy is to integrate RM with Enterprise Architecture (EA). The congruence of RM and EA has been acknowledged rather recently, and there is a limited, but emerging research on the topic advocating a closer connection between the two fields. The research generally concerns how RM principles and requirements could be incorporated into, or supplement EA to enable the management of authoritative information assets (e.g. Becker et al., 2011; Sprehe, 2005; Vieira et al., 2011; Vieira, Valdez, Borbinha, 2011), or how EA can support all-encompassing RM strategies and procedures (e.g. An, 2009; Katuu, 2018a; Katuu, 2018b; Katuu, Ngoepe, 2015; Svärd, 2013).

EA is a tool for analysis, planning and change of organisation and business processes, with the ultimate purpose to meet desired organizational objectives and deliver value to the organization. To achieve this, control and coordination of the organizations' resources and processes is required - to "ensure that the business and IT are in alignment. The enterprise architect links the business mission, strategy and processes of an organization to its information and technology strategy" (ISO/TR 21965:2019(E), p. v). This includes both the fulfilment of direct goals such as providing a certain service to customers, but also non-functional goals such as business-agility - the capability to react to changes. A common definition of architecture is " $[t]$ he fundamental concepts or properties of a system in its environment embodied in its elements, relationships, and in the principles of its design and evolution" (ISO/IEC/IEEE 42010: 2011(E), clause 3.2). EA is characterized by a holistic view of the properties of an enterprise ${ }^{6}$ in its environment; its goals and strategies and its components and their relations to each other and to the whole.

EA is usually considered to have originated in the 1980s (e.g. Sessions, 2007), however it has also been argued that the roots of EA, if not the concept, could be traced back to the early 1960s (Kotusev, 2016). The concept of EA is attributed to the at the time IBM employee John Zachman, who in a couple of articles during the 1980s (Zachman, 1982; 1987) appropriated architechural principles in the planning and development of organizational information systems. The resulting so called Zachman Framework is a structure for describing an enterprise from different views, which has served as a model for many later EA approaches. Following the initial initiatives, several models and frameworks have been developed. ${ }^{7}$

An architecture framework is defined as "conventions, principles and practices for the description of architectures established within a specific domain of application and/or community of stakeholders" (ISO/IEC/IEEE 42010: 2011(E), clause 3.4.). Such could have a more or less narrow focus technological or more comprehensive. ${ }^{8}$ However, several EA frameworks define four basic domains (e.g. TOGAF 9.2, 2018, clause 2.3):

\footnotetext{
${ }^{5}$ Work title, should not be confused with Hans Boom's concept concerning appraisal from a societal perspective. The document goes under different descriptions in Scandinavia. It has some similarities with a records retention plan, but is more comprehensive including for instance classification code, security class, access level, medium, format, storage, system affiliation, disposal etc.

${ }^{6}$ An enterprise could be an organization (private, public, commercial, or non-commercial), units of an organization or a group of organizations - "[t]he highest level (typically) of description of an organization and typically covers all missions and functions. An enterprise will often span multiple organizations" (TOGAF 9.2, 2018, clause 3.38). In the following organization will be used as a generic term covering all forms of enterprises.

${ }^{7}$ The presumption of this paper is that different EA frameworks or models could form the basis for integration with RM, and none particular is advocated here.

${ }^{8}$ One of the most widely known and applied frameworks is TOGAF (the Open Group Architecture Framework), an American industrial standard first issued in 1995. TOGAF is used as the reference framework in ISO/TR 21965:2019(E), the recently issued standard on records management in EA.
} 
- business architecture $e$ - business strategies, governance, organization, and key business processes

- data or information architecture - the structure of an organization's data assets and data management resources

- application or software architecture -the individual applications, their interactions, and relationships to the business processes

- technology or infrastructure architecture - hardware, software and infrastructure required to support the other architectures

It is also common to identify a layer of solution architecture on a tactical level, which focuses on a particular problem or business operation and how IS/IT supports that operation (TOGAF 9.2, 2018, clause 3.69). The business and information domains are not primarily about technology, but about how organizations work and how information is understood, modelled and put to effective use. A central element in EA is thus the control of the organization's information assets, why there is a natural link to RM.

Architecture work is distributed between several coactive roles, in principle corresponding to the domains above. A common role setup is the following (IASA, 2019):

- the enterprise architecture function - a function unifying architecture work in the organization with a holistic perspective

- business architect - participates in the development of business strategies to accomplish specific business goals and secures the relationships between business processes, information flows and systems

- information architect - controls storage, retrieval and integration of information needed to carry out business processes

- solution architect - plans the delivery of IT-solutions based on business needs in order to optimize the value of the solution for the organization

- software architect - realizes solutions by structuring and designing software system applications

- infrastructure architect - creates and delivers technology strategies to optimize the organization's use of technology resources, that is hardware, network, technological platforms and physical systems

The roles could be combined, and for instance the Swedish branch of IASA integrates the information architect with the business architect function, and correspondingly the business and information architecture domains.

The relationship between the roles is shown in figure 3. The EA function works at a high level, with the overall scope of the organisation in mind. The Business Architect reaches out down to technical details and mainly acts as a bridge between the business and technology, and works in pair with the Solution Architect who is more concerned with technical details. Software and Infrastructure Architects normally works together with the Solution Architect. In short, the Business Architect identifies business and user needs to make sure that those are fulfilled, while the Solution Architect provides the required technical services. 


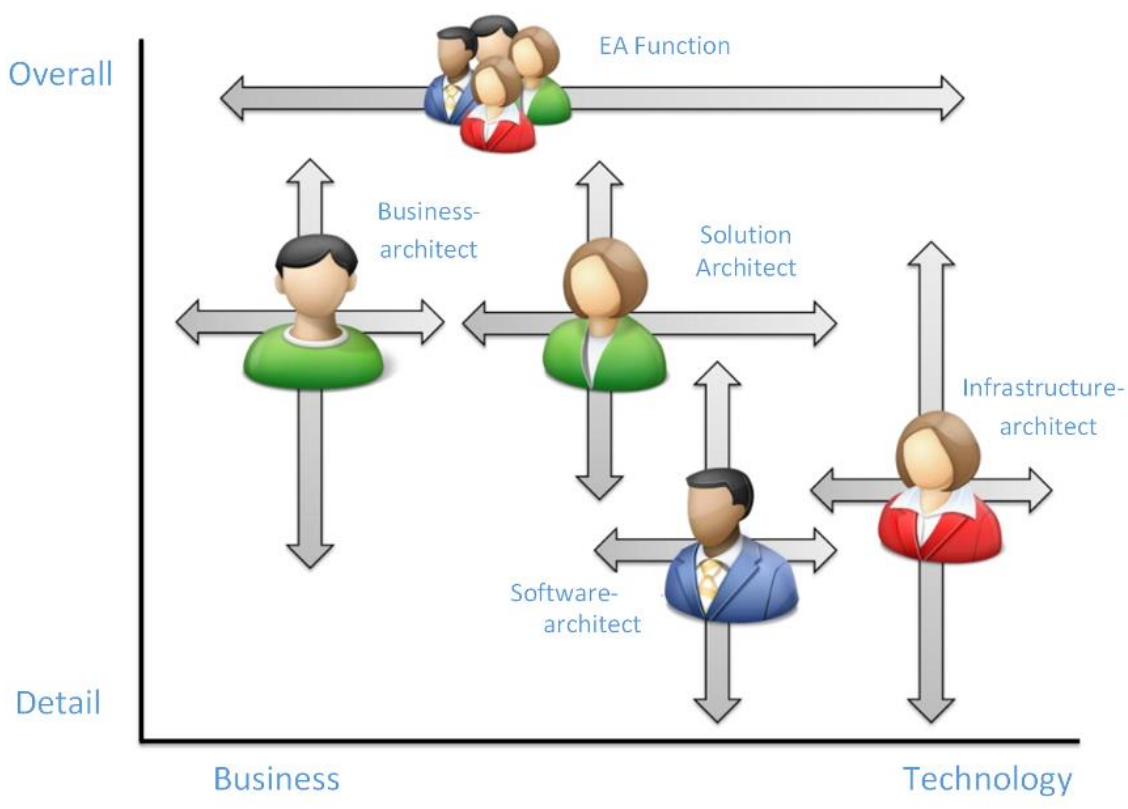

Figure 3. Architecture roles (Akenine et al., 2014: 12, with permission)

\section{The intermesh of RM and EA - a methodological approach}

The problems that RM addresses in contemporary organizations, could be characterized as "wicked problems". That is, they are difficult to pinpoint due to their complexity and interdependences, and one single solution may not be at hand. RM has to take the interests of various stakeholders into consideration (cf. ISO15489-1:2016: vi), navigate within the "new paradigm", and provide continuity in organisations that continuously are forced to adapt to changing circumstances. Those types of problems are not solved by a linear approach, instead a design process way of working can be more successful. Design thinking involves context analysis, identifying problems, ideation and generation of solutions generating, creative thinking, sketching and drawing, modelling and prototyping, testing and evaluating (Cross, 2011). The design thinking process does not take the outset in a problem, but in the users and user needs to understand and assess possibilities before focusing on solutions. Design thinking is closely related to User Experience Design (UX), the process of enhancing user satisfaction by improving the perceived usability and accessibility of a product or a service (e.g. Hassenzahl, Tractinsky, 2006). These approaches have similarities with agile methods for systems development. Traditional systems development dominating during the 1970s and 1980s, e.g. the waterfall model, was based on a linear and sequential logic where changes should be avoided. However, personal computers and network based work processes, flexible organizations and new market relations demanded more flexible solutions and an adaption to more or less continuous change. The agile movement emerged as a response to this development in the end of the $20^{\text {th }}$ century, advocating an evolutionary, incremental and iterative approach (Fowler, Highsmith, 2001). Agile is now an umbrella term for different systems and software development methods, among which the most recognized are SCRUM and Kanban, characterized by among other things a high level of flexibility and a close collaboration with users/customers (Akenine, 2014: 208-210).

The following will describe a model for collaborative work based on agile methods and design thinking, integrating RM and EA. The model is based on the architecture roles (figure 3 above), and shows how RM could collaborate with those and how work tasks and responsibilities could be divided. Figure 4 below shows how RM could work together with EA, Design thinking/UX and agile methods, to develop and implement IG solutions.

The departure is the need for RM in an organization guided by certain rules according to legislation, standards or other commitments. The RM models, described above, contributes with knowledge of RM requirements and the disciplinary artefacts. The Business architect contributes with business analysis and information analysis, and produces relevant artefacts from that perspective. Design 
thinking identifies users and produces user scenarios, use cases and drives the work according to method of insight, hypothesis, prototyping, workshops etc. Agile methods provide a way of doing collaborative work in small steps with agile development teams to build shared knowledge, and help with requirements in the form of scenarios, epics and user stories. The agile team follow the process and secure transparency of the work through a shared Kanban or Scrum backlog, a list of all new features and changes required to reach a particular outcome.

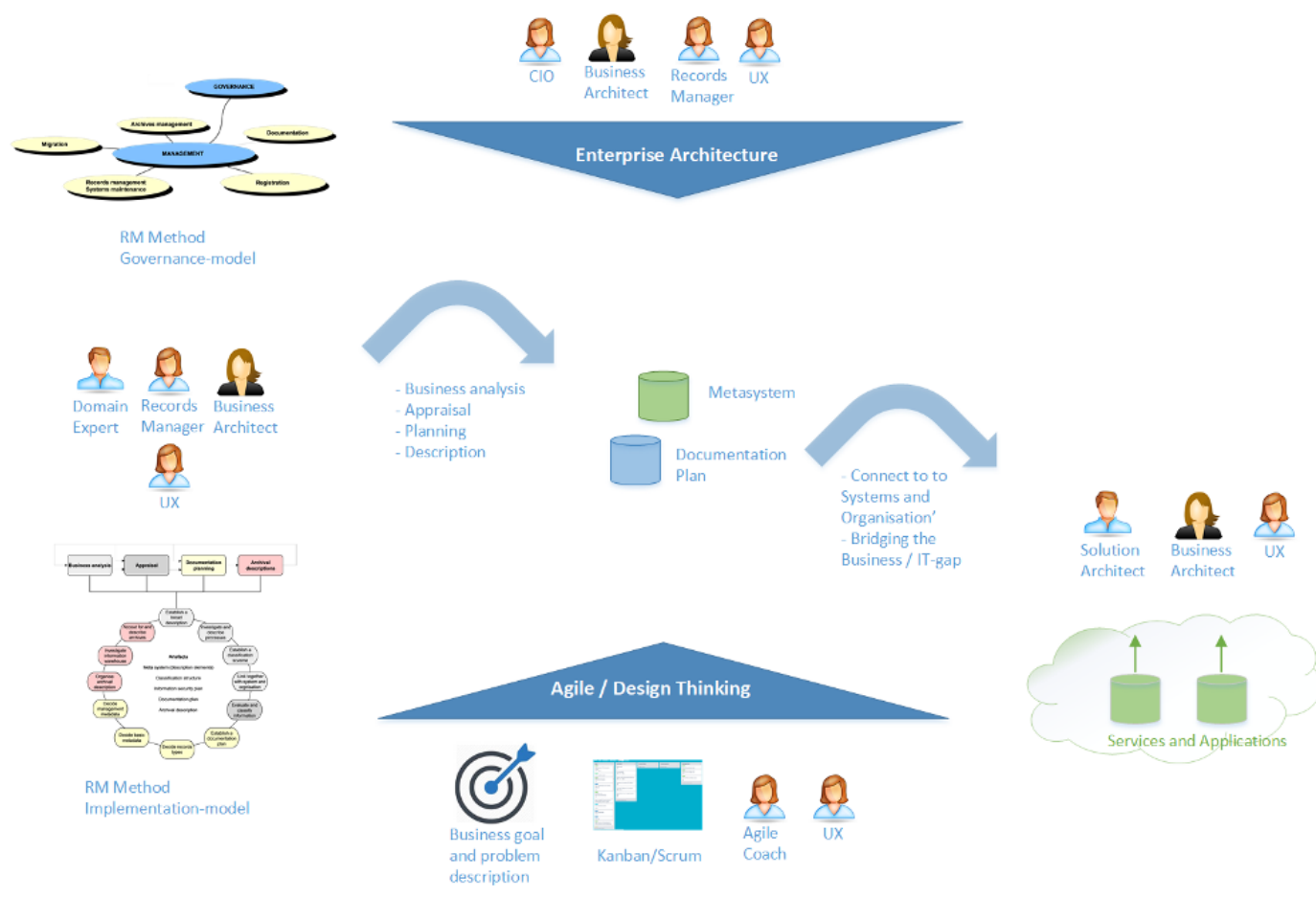

Figure 4. A dynamic work model integrating RM and EA

The figure gives an overview of the method with EA at the top governing the process and agile methods and Design thinking supporting it, while a broad group consisting of several roles or functions perform the steps in the RM method and the transfer to the Solution architect/development team for realization of needed services and applications. This could be done by the agile concept of writing requirements as 'user stories, typically done by the Business Architect with help from UX experts. The starting point is to define the goal and scope of the work, often an underrated activity. Agile methods and Design process methods aid to the building of a common view of the problem and communicating it to the organisation, as well as providing management with the necessary input to plan and follow up work. This can be done in the form of a Design Sprint, a time-constrained, fivephase process used to suggest a solution for a product or service (Banfield et al., 2015), where the Business architect, the Records manager and the Agile and Design process roles participate. Next step is the business analysis, where the Records manager and Business architect work in close collaboration, using an agile approach to address the problem in small steps, and a Design thinking approach using workshops and visualization to collect and analyse large amounts of information in a structured and prioritized way, and feedback to validate the understanding via rapid prototyping. An efficient method in this stage is Capability modelling, which corresponds to the first step in the RM Implementation model. A capability is "[a]n ability that an organization, person, or system possesses" (TOGAF 9.2, 2018, clause 3.30), emerging from the goals and objectives and realized by business processes. Capabilities are stable, high-level representations of what the organization aims to do. Capabilities form the top layer of a business architecture model, and can then be broken down to business process and functions, systems and applications. The capabilities are visualized in a "City map", a graph showing the most important elements in the architecture and why they exist by illustrating value streams (Akenine et al., 2014: 47). Next follows the Business Process analysis, and the city map is here used to map, home in and prioritize the most important activities, and to give an 
overview and context of the work. The city map is also used as input to an agile approach of development, providing a high-level roadmap that helps the agile organisation to prioritize, identify expected applications and the resources needed. This is a typical task for a Business architect with support from domain experts and the Records manager to focus on the information. Typical output is process charts, information models and a first sketch on services that can provide users with necessary information. A design process approach could be used to build early prototypes to verify the findings. This step is followed by the establishment of a business classification, which is performed by the Records manager with input from the previous work process analysis. The business processes should then be aligned with the relevant systems and organizational units, which is the primary domain of the Solution Architect in close collaboration with the Business Architect. This is one of the most crucial parts of any IT development project, bridging the gap between Business and IT (IASA, 2019). Business architecture shows what shall be done, while Solution architecture shows how it shall be done. The agile approach will here help by building work packages that supply development teams with both requirements and priorities for planning. Especially building and maintaining the metasystem is important and should be done using input from the Business architect. Here the Design process way of working contributes with prototypes in the form of templates and feedback from users, to quickly get services and solutions correct. The following step, the appraisal and assessment of information, is primarily RM work, but deliverables and support particularly from the Business architect is needed. Documentation planning is a mix of activities performed by the RM roles and Business architect using design process methods. The last step, Archival description, is a typical RM domain.

\section{Concluding remarks}

The premise of this paper is that RM should be a central feature of IG, and that RM requirements could apply to the management of other organizational information assets. The intermesh of RM principles and EA is a fruitful approach in the development of coherent IG regimes The aim of EA is to support business performance in order to fulfil the organizations' overall mission and enable change and development. A focus on supporting the fulfilment of organizational goals and missions, and the requirements from other stakeholders, is also characterizing RM. EA and RM thus meet in a common mission, aiming at the same basic goal. Modern RM is also concerned with change and continuous improvement (e.g. ISO 30300:2011, clause 2.4.8) and service development, an essential feature of EA. However, the object of EA is the management of the organization as a whole and its assets, while the object of RM is the management of the information assets regarded as records. RM has thus a different mandate, but constitutes an indispensable element if the organization's goals should be fully realized. RM requirements need to be embedded in the domains of EA and the phases of the development of an architecture (ISO/TR 21965:219(E), clause 12.1). RM, on the other hand, needs to adopt methods and tools already developed in EA, which would enhance professional knowledge and performance. The suggested approach is therefore to merge RM work with architecture work, identify roles that work together, and align methods and corresponding deliverables. Of central importance in this process is the Business architect role, which spans over or has connections to almost every other role. The collaboration should start here. An example is business process analysis, which is main concern for contemporary RM, but also the foundation of the Business Architecture. The Records manager and the Business architect should work in close collaboration performing analyses and producing deliverables as city maps, process maps etc., in conjunction with UX experts that drives the process in a design thinking way, and by capturing input from domain experts. EA and RM thus co-function very well in this particular area, but RM also interfaces with other architect roles.

The paper reports the current results of an on-going development project. The next phase will be testing and evaluating the work model. Further R\&D activities could include a systematic mapping of the elements of RM principles and different EA frameworks in whole. 


\section{References}

Akenine, D., Toftefors, J., Berg, C., Kammerfors, E., Folkesson, R., Olsson, S. H. (2014). Boken om IT-arkitektur. Helsingborg: HOI Förlag

An, X. (2009). The electronic records management in e-government strategy: case studies and the implications. // 2009 International Conference on Networking and Digital Society 1, 17-20

Banfield, R., Lombardo, C. T., Wax, T. (2015). Design sprint: A practical guidebook for building great digital products. O'Reilly Media, Inc.

Becker, C., Antunes, G., Barateiro, J., Vieira, R., Borbinha, J. (2011). Modeling digital preservation capabilities in enterprise architecture. // Proceedings of the 12th Annual International Digital Government Research Conference: Digital Government Innovation in Challenging Times. ACM, 84-93

Bergbom, R., Forsberg, J. E.. Hagstedt, R., Sahlén, T. (1992). Den goda visionen: om kontorsinformationssystem i offentlig miljö. Älvsjö: Kommentus

Bodin, S., Sahlén, T., Sjögren, C. (2000). Dokumenthantering i företag och organisationer: en kvalitetsfråga. Stockholm: Folkrörelsernas arkivförbund

Brooks, J. (2019). Perspectives on the relationship between records management and information governance. // Records Management Journal 29, 1-2, 5-17

COBIT 5: A Business Framework for the Governance and Management of Enterprise IT. ISACA. https://www.isaca.org/COBIT/Pages/COBIT-5.aspx (30.8.2019)

Cross, N. (2011). Design thinking: understanding how designers think and work. Oxford-New York: Berg

Denscombe, M. (2014). The good research guide: for small-scale social research projects, $5^{\text {th }}$ ed. Berkshire: McGraw-Hill Education

Fowler, M., Highsmith, J. (2011). The agile manifesto. // Software Development 9, 8, 28-35

Gartner Inc. (2019). https://www.gartner.com/it-glossary/information-governance/ (30.8.2019)

Generally Accepted Recordkeeping Principles®: Information Governance Maturity Model. Overland Park, KS: ARMA International, $2013 \mathrm{https} / / /$ rim.ucsc.edu/management/images/ThePrinciplesMaturityModel.pdf (30.8.2019)

Hagmann, J. (2013). Information governance-beyond the buzz. // Records Management Journal 23, 3, 228-240

Hassenzahl, M., Tractinsky, N. (2006). User experience-a research agenda. // Behaviour \& information technology 25, 2, 9197

IASA Global. (2019). https://iasaglobal.org/itabok-1/engagement-model/role-descriptions/ (30.8.2019)

International Council on Archives (2007). ISDF - International Standard for Describing Functions

ISACA. (2019). https://www.isaca.org/Pages/Glossary.aspx (30.8.2019)

ISO 15489-1:2016 Information and documentation — Records management — Part 1: Concepts and principles

ISO 30300:2011 Information and documentation - Management systems for records - Fundamentals and vocabulary

ISO 30301:2011 Information and documentation — Management systems for records — Requirements

ISO/IEC 38500:2015 Information technology — Governance of IT for the organization

ISO/IEC/IEEE 42010: 2011(E) Systems and software engineering - Architecture description

ISO/TR 21965:2019(E) Information and documentation - Records management in enterprise architecture

Katuu, S. (2018). Using Enterprise Architecture as a means of understanding institution technology ecosystems. // Proceedings of the ICMLG 2018 16th International Conference on Management Leadership and Governance. Academic Conferences and Publishing International, 130-138

Katuu, S. (2018). The Utility of Enterprise Architecture to Records and Archives Specialists. // 2018 IEEE International Conference on Big Data (Big Data). IEEE, 2702-2710

Katuu, S., Mpho N. (2015). Managing digital records in a South African public sector institution. // INFuture 2015: eInstitutions Openness, Accessibility. and Preservation, 135-141

Kotusev, S. (2016). The history of enterprise architecture: An evidence-based review. // Journal of Enterprise Architecture $12,1,29-37$

Kotusev, S. (2019). Enterprise architecture and enterprise architecture artifacts: Questioning the old concept in light of new findings. // Journal of Information Technology 34, 2, 102-128

Lomas, E. (2010). Information governance: information security and access within a UK context. // Records Management Journal 20, 2, 182-198

Reed, B. (2017). Recordkeeping in Information Governance. Information Governance ANZ. https://www.infogovanz.com/recordkeeping-in-information-governance (30.8.2019)

Saffady, W. (2015). Records management or information governance? // Information Management 49, 4, 38-41

Sahlén, T. (2016). Informationsforvaltning - i offentlig och privat sektor. Stockholm: Näringslivets Arkivråd

Sessions, R. (2007). A comparison of the top four enterprise-architecture methodologies. Houston: ObjectWatch Inc. http://www3.cis.gsu.edu/dtruex/courses/CIS8090/2013Articles/A\%20Comparison\%20of\%20the\%20Top\%20Four\%20E nterprise-Architecture\%20Methodologies.html (30.8.2019)

Sprehe, J. T. (2005). The positive benefits of electronic records management in the context of enterprise content management. // Government Information Quarterly 22, 2, 297-303

Sundqvist, A. (2005). (ed.). Dokumentstyrning i processorienterade organisationer. Stockholm: Folkrörelsernas arkivförbund \& Näringslivets arkivråd

Svärd, P. (2013). Enterprise Content Management and the Records Continuum Model as strategies for long-term preservation of digital information. // Records Management Journal 23, 3, 159-176.

TOGAF® Standard. (2018). Version 9.2, C182. The Open Group. https://pubs.opengroup.org/architecture/togaf9doc/arch/index.html (30.8.2019)

Vieira, R., Valdez, F., Borbinha, J. (2011). An Analysis of MoReq2010 from the Perspective of TOGAF. // International Conference on ENTERprise Information Systems. Springer, Berlin, Heidelberg, 335-344 
A. Sundquist, T. Sahlén, M. Andreasen. The Intermesh of Records Management...

Vieira, R., Borbinha, J., Valdez, F., Vasconcelos, A. (2011). A reference architecture for records management. // Proceedings of the $12^{\text {th }}$ Annual International Digital Government Research Conference: Digital Government Innovation in Challenging Times. ACM, 339-340

Zachman, J. A. (1982). Business systems planning and business information control study: a comparison. // IBM Systems Journal 21, 1, 31-53

Zachman, J. A. (1987). A framework for information systems architecture. // IBM systems journal 26, 3, 276-292 